\title{
Estrutura de governança das transações econômicas e políticas públicas de auporte a arranjos e sistemas produtivos locais: estudo da cadeia têxtil da Bahia e São Paulo
}

Governance structure of economic transactions and public policies to support clusters: study of the textile chain in Bahia and São Paulo

Estructura de gobernanza de las transacciones económicas y políticas públicas de apoyo a clusters: estudio de la cadena textil en Bahía y São Paulo

\section{Resumo}

Esta pesquisa objetiva, por intermédio dos fatores ligados à escolha da estrutura da governança privada dos empresários, examinar como os atributos das transações econômicas foram capazes de influenciar a regulação das políticas públicas na Bahia e em São Paulo. Para tanto foram entrevistados empresários da cadeia têxtil nos estados pesquisados no intuito forma de examinar as características das transações econômicas desses empresários, bem como a estrutura de governança empregada. Os dados foram analisados qualitativamente por meio de análise de conteúdo. Como resultados observou-se os diversos tipos de transação econômica possuem certa influência sobre a regulação das políticas públicas. Em especial as transações que possuem características com necessidade de controle são as que mais estimulam a regulação. Conclui-se que para além dos indivíduos, grupos e organizações, as transações econômicas e estruturas de governança das transações do ramo têxtil de São Paulo e na Bahia representam uma importante influencia na regulação de políticas públicas estaduais de suporte a arranjos e sistemas produtivos locais.

Palavras-chave: Transações econômicas; Estrutura de governança; Política pública; Arranjos e sistemas produtivos locais.

\begin{abstract}
This article aims, through the factors linked to the choice of the structure of private governance of entrepreneurs, to examine how the attributes of economic transactions were able to influence the regulation of public policies in Bahia and São Paulo. To this end, entrepreneurs from the textile chain in the surveyed states were interviewed as a way of examining the characteristics of these entrepreneurs' economic transactions, as well as the governance structure employed. The data were analyzed qualitatively through content analysis. As a result, it was observed that the various types of economic transaction have a certain influence on the regulation of public policies. In particular, transactions that have characteristics in need of control are those that most stimulate regulation. It is concluded that in addition to individuals, groups and organizations, economic transactions and governance structures of transactions in the textile sector of São Paulo and Bahia represent an important influence in the regulation of state public policies to support local productive arrangements and systems.
\end{abstract}

Keywords: Economic transactions; Governance structure; Public policy; Clusters.

\section{Resumen}

Este artículo tiene como objetivo, a través de los factores vinculados a la elección de la estructura de gobierno privado de los empresarios, examinar cómo los atributos de las transacciones económicas pudieron influir en la regulación de las políticas públicas en Bahía y São Paulo. Para ello, se entrevistó a empresarios de la cadena textil de los estados encuestados, como una forma de examinar las características de las transacciones económicas de estos empresarios, así como la estructura de gobernanza empleada. Los datos se analizaron cualitativamente mediante análisis de contenido. Como resultado, se observó que los distintos tipos de transacciones económicas tienen cierta influencia en la regulación de las políticas públicas. En particular, las transacciones que tienen características que necesitan control son las que más estimulan la regulación. Se concluye que además de los individuos, grupos y organizaciones, las transacciones económicas y las estructuras de gobernanza de las transacciones en el sector textil en São Paulo y Bahía 
representan una influencia importante en la regulación de las políticas públicas estatales de apoyo a los arreglos y sistemas productivos locales.

Palabras clave: Transacciones económicas; Estructura de gobierno; Política pública; Clusters.

\section{Introdução}

As estruturas de governança para organização das atividades de produção, comercialização e distribuição de produtos e serviços vêm sendo analisadas por distintas pesquisas no âmbito da Nova Economia Institucional (NEI), em especial pela Economia dos Custos de Transação desenvolvida por Williamson (1985). A teoria considera que os custos de transação podem ser suavizados a medida que se escolhe bem a governança. Para tanto se faz necessário considerar que as transações econômicas constituem a unidade de análise para o entendimento das governanças.

A discussão a respeito das governanças ganha também relevância associada às políticas públicas. A Nova Economia Institucional fala a respeito da influência das instituições de governança sobre as políticas públicas. O acabou teórico assegura o poder das instituições, inclusive os grupos e indivíduos envolvidos, sobre a maneira como desenvolvidas as políticas públicas. O apoio público, segundo a NEI, sofreria influência das instituições e atores que formam as governanças.

Apesar dos esforços da NEI, existem diversos entraves não superados e não previstos nas discussões conceituais a respeito da governança em empresas ligadas a Arranjos e Sistemas Produtivos Locais (ASPLs). (Villela \& Pinto, 2009). Os aspectos relacionados à governança têm sido bem explorados na literatura, fazendo com que suas definições fossem adaptadas por uma vasta gama de estudos (Mendes-da-Silva et. al., 2008). No entanto, em termos práticos, diversas questões não foram adequadamente operacionalizadas na implementação das políticas públicas de apoio a ASPLs.

Distintas políticas públicas de apoio aos arranjos vêm sendo adotadas no Brasil. Contudo, o esforço de compreensão dos aglomerados nem sempre tem acompanhado a implementação dessas políticas. As intervenções estaduais, bem como as federais, são recentes e demandam a necessidade de um arcabouço teórico mais robusto. Uma das maneiras de alcançar esse intento é apreender a respeito de aspectos relativos à governança de empresários apoiados por políticas estaduais de ASPLs.

Os esforços teóricos previstos para esta pesquisa são justificados também empiricamente, uma vez que o estudo dos ASPLs conforme assevera Sabóia (2007, p. 23) "funciona como uma lente para perceber os movimentos e as questões locais" de tal forma que a análise dos processos de formação e desenvolvimento dos Arranjos e Sistemas Produtivos Locais se revela como importante instrumento analítico e de ação política de desenvolvimento local (Vecchia, 2006). Essa investigação assume, nesse sentido, um papel de relevância social ao colaborar com as discussões a respeito da governança em empresas ligadas a ASPLs e apoiados por políticas públicas.

Mesmo diante da existência de distintos estudos a respeito da influência das instituições sobre as políticas públicas, existe ainda um vasto campo na literatura a ser explorado. Considerando que as governanças em ASPLs são formadas por indivíduos, grupos, instituições, bem como por estruturas (mercado, hierarquia e híbrida), torna-se oportuno estudar, por exemplo, a influência das estruturas escolhidas -por meio de suas transações- sobre as políticas, o que é a proposta desta pesquisa.

Com foco no neoinstitucionalismo econômico que mira nas instituições formais, este estudo objetivo responder a pergunta: Qual a influência da estrutura de governança utilizada nas transações econômicas inter organizacionais sobre as regulação formal em políticas públicas estaduais para ASPLs? Visa, por meio dos fatores ligados à escolha da estrutura da governança privada dos empresários, examinar como os atributos das transações foram capazes de influenciar a regulação das políticas. A regulação se refere às regras e instituições formais que normatizam as ações dos atores inseridos na política.

A literatura nacional e internacional carece de estudos que examinem de acordo com as características das transações que definem as estruturas de governança- especificidade dos ativos, frequência e incerteza nas transações - as influências sobre a regulação das políticas públicas de apoio. No caso dos arranjos da cadeia têxtil na Bahia e em São Paulo 
inexistem pesquisas a respeito da estrutura e dos mecanismos utilizados pelas governanças, o que impossibilita entender a influência desses aspectos sobre a regulação da política de apoio.

Ao objetivar compreender como a estrutura escolhida pela governança dos empresários envolvidos nos ASPLs é capaz de influenciar determinadas características das regras criadas pelas políticas públicas, o estudo apresenta esforços teóricos e empíricos importantes para o estudo das governanças e das políticas públicas. Reconhece-se assim a importância de explorar temas que envolvam governança inter organizacional de empresários e o melhor funcionamento e desempenho das políticas públicas.

\section{Referencial Teórico}

\subsection{Nova Economia Institucional (NEI)}

As instituições aqui são entendidas por intermédio da Nova Economia Institucional (NEI), como regras formais, explicitas, constituídas que podem promover o desenvolvimento econômico (North, 1990). A NEI se concentrou no papel das instituições de forma macro analítica integrando a abordagem da teoria institucional de North (1990), e micro analítica com a Economia dos Custos de Transação (ECT) de Williamson (1985, 1991, 1996).

Torna-se relevante evidenciar então a distinção das abordagens preconizadas por Williamson e North. Os dois autores enfocaram os custos de transação, no entanto, Williamson se volta a estudar os custos de transação com arranjos organizacionais, ou seja, das estruturas de governança, enquanto North afirma que os custos de transação podem ser diminuídos por instituições eficientes.

As instituições, sob a ótica de North (1990), se referem às regras do jogo e regulam/disciplinam as atividades das organizações quanto dos indivíduos. Por conta da existência da incerteza e como forma de minimizar custos de transação é que surgem as instituições. O autor destaca, em especial, os estudos que relacionam instituições e desenvolvimento econômico. Assim, as instituições representariam uma restrição nas escolhas individuais nas transações econômicas dos atores. Ao impor restrições as instituições diminuiriam também as possibilidades de escolha dos indivíduos, mas não apenas isso. Além do papel de restrição, as instituições podem representar uma função construtiva na interação entre agentes por objetivarem minimizar as incertezas futuras e gerar um ambiente mais estável. North (1991) afirma que uma estrutura institucional eficiente poderia diminuir custos de transação por conta de conseguir amenizar a incerteza e melhorar a coordenação entre atores e organizações.

As instituições de North dividem-se ainda em informais e formais. As instituições informais representariam significados coletivos, construídos na interação social e expressos pro meio das normas ou código de conduta, vinculados, por exemplo, às religiões, costumes e tradições (WILLIAMSON, 2000). Já as formais se referem às regras codificadas em sistemas simbólicos como os vinculados às línguas, ou seja, pelos alfabetos e normas de sintaxe e semântica que regem a escrita. Nesse caso podemos dizer que instituições formais são as regras escritas que regem as ações dos atores sociais, entre eles as organizações. Portanto podemos operacionaliza-las como regras escritas que compõem o sistema legal e todas as formas contratuais existentes em uma dada sociedade que são desenvolvidas por um agrupamento social para a solução de um problema vivenciado. São exemplos de instituições formais a constituição; as leis; os decretos do executivo; as regras criadas pelas agências reguladoras; as políticas públicas como as que regem os Arranjos e Sistemas Produtivos Locais (ASPL); os contratos sociais e estatutos das empresas; e os contratos em geral. As instituições formais como definidas na NEI são objeto de interesse deste trabalho. Mais especificamente a regulação das políticas públicas de apoio aos ASPLs (instituições formais da governança pública).

Por sua vez, a ECT de Oliver Williamson, possui foco na minimização de custos de transação por intermédio de governanças mais adequadas, ou seja, estuda as instituições que regulam as transações em nível mais microanalítico. Essas 
estruturas de governança são capazes de ocorrer via mercado, formas híbridas ou integração vertical, determinadas por meio das características da transação e dos pressupostos comportamentais envolvidos. Assim, de forma resumida, a teoria determinou alguns importantes condicionantes: a) os pressupostos comportamentais (racionalidade limitada e oportunismo); b) o ambiente institucional (formal e informal); c) as características das transações que determinam as estruturas de governança (especificidade de ativos, frequência das transações e incerteza nas transações).

A respeito dos pressupostos comportamentais envolvidos, considera-se que os indivíduos são oportunistas, ou seja, existiria um auto interesse do indivíduo que o faz capaz de enganar, mentir, descumprir condições. O oportunismo se dá através do uso incompleto ou distorcido da informação, que gera a racionalidade limitada dos agentes. (WILLIAMSON, 1985). Sob essa consideração, os contratos são considerados incompletos, e por conta disso, torna-se necessário que empresários se utilizem de mecanismos de coordenação complementares, as governanças. Governanças essas que contam com instituições capazes de regular indivíduos e organizações.

Com relação ao ambiente institucional, o conceito de Williamson $(1985,1990)$ versa mais especificamente a respeito das instituições da governança com enfoque analítico das formas contratuais que regem as transações. Essas instituições são divididas em formais e informais e empregadas como forma de garantir a eficácia da transação (Williamson, 1996; North, 1991). Os autores neoinstitucionalistas consideram os mecanismos formais/instituições formais como parte do contrato econômico, em que os elementos formais representariam os termos presentes em um contrato, enquanto os elementos informais representam estruturas de interação.

As instituições informais de governança são representadas por salva guardas reputacionais e outros mecanismos sociais. Segundo Ménard (2004) são alguns exemplos de instituições informais a reputação, confiança, compartilhamento de informações e ajuda mútua. Todos eles utilizados na coerção dos agentes.

As instituições formais de governança dizem respeito aos contratos, estatutos e normas regimentais que são arranjados de forma proposital pelos atores. Compreendem-se aqui as estruturas regulatórias formais (contratos formais) que se referem a regras e restrições de autonomia e ação das partes. Considerando que as transações são passíveis de custos e como resposta aos riscos dessa transação, os responsáveis por organizações comumente desenvolvem contratos que preveem soluções contingenciais e/ou resultados não previstos. (Poppo; Zenger, 2002). Deve-se considerar, no entanto, que os contratos são considerados incompletos, e apesar de poder prever situações futuras, não são capazes de antever todas as variáveis existentes numa transação, bem como perceber todas as contingências que podem surgir durante o período de sua vigência (Bergamacshi, 2004).

Como forma de minimizar os problemas da incompletude contratual desenvolvem-se então os mecanismos de coordenação complementares: as estruturas de governanças. Conforme a Economia dos Custos de Transação, as propriedades das transações é que determinam o tipo de estrutura de governança mais adequada, ou seja, mais eficiente. Williamson (1975, 1991) caracterizou as estruturas de governança como mecanismos de coordenação empregados pelas empresas visando diminuir custos de transação anteriores e posteriores a transação, além de despesas de operação. Definiu a transação como sempre que existe a transferência de um bem através de uma interface tecnologicamente separável. Os custos de uma transação referem-se aos custos totais associados a uma transação, ou seja, os custos de negociar, redigir e garantir o cumprimento contratual.

O autor (1990) distinguiu ainda três tipos de estruturas de governança: mercados, hierarquias e híbridas. Williamson procura verificar se as transações são conduzidas por mecanismos de preço (mercado), em outro extremo dirigidas por hierarquias conferidas pelos atores do processo (hierarquias), ou ainda resultam de uma estrutura intermediária e mista de coordenação, em que ocorrem interações mais frequentes com maior nível de colaboração e cooperação nas relações (formas híbridas). 
As três formas de governança mencionadas se diferem pela maneira de coordenação e controle, e dependem de três aspectos das transações: a incerteza que envolve o ambiente (podendo ser incerteza tecnologia ou de mercado), o grau de especificidade dos ativos envolvidos na efetivação da transação, e a frequência de ocorrência da transação. A incerteza seria responsável por produzir uma maior necessidade de controle das transações econômicas. A frequência se refere à quantidade de vezes que ocorrem essas transações, e a medida que se tem alta frequência aumenta-se também a dependência entre as partes contratantes. Já a especificidade dos ativos diz respeito a um prejuízo de valor dos ativos caso a transação não seja executada. Dessa forma, caso a transação tenha alta especificidade de ativos mais necessário se faz um controle intermediado por uma governança mais especializada. Wiliamson salienta ainda que diante de uma baixa especificidade de ativos a governança a ser escolhida será o mercado.

Os atributos das transações discriminados, segundo o autor, possuem a capacidade de indicar qual estrutura de governança é a mais acertada. Se escolhida de forma correta, a estrutura minimizaria custos de transação e operação e tenderia a ser eleita no longo prazo em detrimento de formas menos eficientes. (Williamson, 1985, 1996).

\subsection{ASPLs, o apoio público e o setor têxtil nos estados}

A partir de outros enfoque internacionais, e como forma de produzir uma definição das aglomerações voltada à realidade do país, o governo federal brasileiro, a partir de conceito criado pela RedeSist, adotou em 2004 o termo Arranjo e Sistema Produtivo Local (ASPL). No Brasil, os arranjos e sistemas produtivos locais (ASPLs) surgem como alternativa capaz de promover o desempenho de MPEs e o crescimento econômico dos territórios ou setores específicos nos quais se inserem por meio do trabalho cooperativo (Lastres \& Cassiolato, 2003). Os autores sintetizam as características básicas dos arranjos e sistemas produtivos locais salientando a dimensão territorial; diversidade de atividades e atores econômicos, políticos e sociais; conhecimento tácito; inovação e aprendizado interativos; governança do ASPL ${ }^{1}$; grau de enraizamento.

Diante da importância econômica e regional dos arranjos, o apoio público estatal no Brasil se fortaleceu a partir dos anos 2000. As políticas brasileiras de ASPLs comumente possuem como um dos principais atores os Estados, mas possuem parcerias e cooperação com a federação e municípios. As políticas públicas de ASPLs representam uma demonstração da força dos Estados de coordenação e da capacidade de se relacionar com outros níveis de governo e com entes não governamentais.

Destaca-se aqui as políticas públicas estaduais da Bahia e de São Paulo. No estado da Bahia, a criação da SECTI (Secretaria de Ciência, Tecnologia e Inovação da Bahia), em 2003, é considerada como o ponto de partida para o apoio público no desenvolvimento de ASPLs na Bahia, estruturadas institucionalmente em torno da RedeAPL. No entanto, o Núcleo Estadual de Apoio ao Desenvolvimento dos Arranjos Produtivos Locais foi formalizado apenas em 2007 pelo Decreto $\mathrm{n}^{\circ}$ 10.431, do dia 24 de Agosto. O suporte aos ASPLs se iniciou mesmo antes da criação do Núcleo Estadual por meio do Programa de Fortalecimento da Atividade Empresarial - O PROGREDIR, que, em julho de 2006, em parceria com o BID, formalizou o contrato de empréstimo ao governo do estado, beneficiando onze arranjos de distintas cadeias econômicas do estado.

Por sua vez, a rede paulista de ASPLs foi concebida por meio do instrumento de formalização Resolução SD - 7 de 13/07/2007. Alguns anos depois, o Programa Estadual de Fomento aos APLs de São Paulo foi então criado e normatizado por intermédio do Decreto Estadual n ${ }^{\circ}$ 54.654, de 7 de agosto de 2009, visando financiar projetos com o intuito de solidificar tanto arranjos como aglomerados produtivos. Por meio do apoio a esses empresários busca-se o desenvolvimento econômico integrado. Os órgãos vinculados ao suporte são: Centro Paula Souza (CPS); Instituto de Pesquisa Tecnológicas (IPT); Instituto

\footnotetext{
${ }^{1} \mathrm{Na}$ literatura a respeito dos ASPLs o tema da governança do ASPL ganha destaque. Deve-se ressaltar, no entanto, que a governança do ASPL ou do grupo de empresários não é alvo desta investigação, mas a governança das transações econômicas inter organizacionais nos ASPLs.
} 
de Pesquisas Energéticas e Nucleares (IPEN); Junta Comercial do Estado de São Paulo (JUCESP); e Agência Paulista de Promoção de Investimentos e Competitividade.

Dentre os arranjos apoiados pelas políticas citadas destacamos nesse estudo dois ASPLs do setor têxtil nos Estados de São Paulo e na Bahia. No estado de São Paulo o arranjo produtivo têxtil de Americana. A cidade, junto com outros quatro municípios vizinhos, aparece como um dos maiores produtores da indústria têxtil no Brasil. No início dos anos 2000, o aglomerado têxtil foi incluído ao projeto de Apoio à competitividade de empresas localizadas em Arranjos Produtivos Locais, bem como na Rede paulista de APLs. O arranjo têxtil passou então a contar com o apoio de 27 organizações públicas e privadas. O ASPL teria sido caracterizado incialmente com importantes esforços no intuito de alcançar uma melhor cooperação, mas com entraves na formação de novas parcerias entre os membros devido à falta de cooperação entre os membros integrantes. (Amato Neto, 2009).

O desenvolvimento da concepção do arranjo produtivo foi iniciada pelo SEBRAE/SP em conjunto com os Sindicatos de produtos têxteis da região de Americana. Logo o projeto foi apoiado pela FIESP e Secretaria de Desenvolvimento Econômico (SD). A governança do arranjo, conforme informações do GT/APL (2004), é compreendida como um grupo de pessoas físicas e jurídicas com disponibilidade para liderar e organizar o trabalho dos atores, coordenar esforços, negociar processos e desenvolver a construção e disseminação de conhecimento específico.

Por sua vez, o ASPL baiano concentra-se no bairro do Uruguai, na Cidade de Salvador. O bairro possui uma importante vocação consolidada na produção de confecções desde os anos 1940. O setor de confecções se configura como importante motor de crescimento, emprego e renda do território ao qual pertence. A região conta com diversas empresas, em especial de vestuário, com destaque para o Shopping Center Bahia Outlet Center. São mais de 30 indústrias de confecções, o que representa em torno de $20 \%$ das indústrias de confecções de Salvador e $10 \%$ do estado.

O aglomerado de Confecções ganhou status de Arranjos e Sistema Produtivo Local por conta da existência do número de empresas reunidas e da representatividade social e econômica para a região. Outrossim, outros aspectos foram considerados: capital humano e competências locais; governança estabelecida; dimensão empresarial (fatores ou condicionantes de domínio das empresas); dimensão estrutural (fatores ou condicionantes relacionados ao mercado e a tecnologia); dimensão Sistêmica (fatores ou condicionantes macroeconômicos). (Secti, 2010).

Diante do potencial e dificuldades apresentadas, o suporte ao arranjo de Confecções teria representado um desejo de desenvolver as atividades das empresas envolvidas e os aspectos sociais e econômicos do território. Durante o ano de 2007, por meio do Decreto Estadual no 10.431/07, foi criado o Núcleo Estadual de Apoio ao Desenvolvimento dos Arranjos Produtivos Locais da Bahia (NE-APLs/BA). Esse decreto priorizou o setor de confecções como prioritário para a economia estadual e o ASPL passou a obter o suporte da principal política pública de apoio no estado, o Programa de Fortalecimento da Atividade Empresarial (Progredir). No total 32 empresas da indústria de confecções passaram a contar com o suporte do Progredir.

\subsection{Políticas públicas e regulação}

As políticas públicas possuem são estudadas de forma bastante holísticas, mas de maneira geral possuem uma característica em comum: todas elas centram nos governos, ou seja, onde são desenvolvidos os interesses, as prioridades e as ideias. Nesse sentido, as discussões a respeito giram em torno de examinar o papel dos governos na definição e implementação de políticas públicas. E, dentro desse contexto de exame dos governos, são estudadas também, por meio das instituições, a função da regulação em políticas públicas.

As políticas públicas constituem instituições formais, ou seja, normas e regras codificadas, a exemplo de leis, decretos, emendas constitucionais, regulamentações, etc. Enquanto instituições formais regulam o comportamento dos atores envolvidos. (Rocha, 2004). No entanto, as políticas públicas não representam apenas isso. Referem-se ainda a uma colisão de 
ideias entre grupos interessados que desenvolvem a análise das funções do governo apresentando-se como solucionadoras de problemas sociais, econômicos, etc. As definições de políticas públicas são bem mais amplas que as definições de regulação. A regulação, definida por meio das instituições, representaria apenas um aspecto das políticas.

Nas pesquisas a respeito da regulação, as políticas públicas têm sua base em outras teorias, a exemplo do neoinstitucionalismo. Dentro da teoria é possível encontrar diversas contribuições a respeito do debate sobre influência das instituições sobre a predileção dos decisores. A teoria da escolha racional refere-se às políticas públicas como questões de ação coletiva e de distribuição de bens coletivos em que são necessários incentivos seletivos visando minimizar interesses pessoais. De igual forma, para o institucionalismo histórico e o estruturalista, as instituições são capazes de influenciar as decisões dos policy makers considerando que existe o interesse pessoal dos agentes. Contudo, no que diz respeito às decisões públicas, devem ser considerados ainda os processos institucionais de socialização, as novas ideias, e os processos criados historicamente por cada país, estado, município (Souza, 2006).

A teoria neoinstitucionalista, associa as instituições formais e informais às políticas públicas, afirmando a força dessas instituições - juntamente com os grupos e indivíduos que compõem as políticas - sobre a forma como se apresenta determinada política pública. Ou seja, destaca a força das instituições/regras formais (no sub-ramo do neoinstitucionalismo econômico) e informais (no sub-ramo do neoinstitucionalismo sociológico) sobre as políticas públicas.

Concentrando-se especificamente no neoinstitucionalismo econômico, arcabouço teórico desse estudo, as políticas públicas poderiam sofrer influência por intermédio de diversas instituições formais. Instituições formais conforme definido por Douglass North nas seções anteriores. Assim, não apenas os indivíduos ou grupos envolvidos possuiriam força para influenciarem políticas, mas também normas institucionais formais são capazes de sugerir novas escolhas políticas. Conforme descrito por North (1991), as instituições possuiriam um papel de restrição nas escolhas individuais dos atores representariam uma restrição nas escolhas individuais nas transações econômicas dos atores, bem como se desenvolveriam um papel construtivo na relação entre os indivíduos.

\section{Procedimentos Metodológicos}

Escolheram-se, como forma de estudar empiricamente a questão proposta pelo estudo, dois casos da indústria de Confecções e Têxtil. O primeiro, o ASPL de Confecções na região do Uruguai, em Salvador, na Bahia. E o segundo o ASPL de Têxtil e Confecções da região de Americana, São Paulo. Os dois ASPLs possuem destaque e notoriedade em seus Estados. O setor econômico têxtil foi escolhido considerando: 1) As características do setor e natureza do negócio (a exemplo do fato de cada empresa representar uma parte da cadeia, ou seja, cada uma é responsável por parte da produção) como forma de encontrar qualquer uma das estruturas possíveis postas pela literatura; 2) Os possíveis tipos de transação encontrados- visando se deparar com um setor que não seja previsível encontrar determinado tipo de estrutura de governança; 3) Mesmo setor na Bahia e em São Paulo como forma de permitir diferenciações e comparativos; 4) Viabilização da pesquisa com base no conhecimento e experiência do pesquisador. Os aspectos discriminados permitem conceber que a pesquisa é capaz de obter resultados robustos, de impacto social e acadêmico.

O método de casos previsto para análise das governanças dos empresários do setor de confecções se filia à abordagem qualitativa utilizada em coleta de dados na área de estudos organizacionais. O método qualitativo empregado busca reter a dinâmica da natureza das entrevistas que serão formatadas por meio da matriz de amarração proposta a seguir. $\mathrm{O}$ foco, nesse sentido, está nos dados que o método pode oferecer com a intenção de descrever e entender as características desejadas.

A pesquisa encontra-se dividida em cinco etapas, descritas a seguir: 
$1^{a}$ etapa: Revisão da Literatura. Dividido em duas subetapas: Subetapa 1: Revisão da literatura a respeito dos conhecimentos teóricos já existentes a respeito do tema; Subetapa 2: Revisão dos estudos a respeito do tema com foco nos procedimentos metodológicos utilizados pelos pesquisadores;

$2^{\mathrm{a}}$ etapa: Coleta de dados. No primeiro momento, anterior à coleta de dados, existiu uma fase de geração e validação dos roteiros das entrevistas com empresários ou especialistas acadêmicos. As entrevistas representaram a principal estratégia de coleta desse estudo. Ademais, o recolhimento de dados foi realizado também por meio de pesquisas bibliográficas, documental e entrevistas.

O número de empresas pesquisadas foi definido por meio da saturação teórica dos dados. Como forma de evitar viéses foi utilizado um roteiro de pesquisa. Nas entrevistas os empresários do setor têxtil indicaram as caractrerísticas das transações no intuito de verificar a estrutura de governança mais utilizada. Os participantes da pesquisa foram sugeridos por meio de sindicatos e associações do setor têxtil que representam as áreas geográficas em estudo.

No estado de São Paulo foram entrevistados doze representantes de micro, pequenas e médias empresas do setor têxtil de diversos elos da cadeia: fiação, tecelagem, malharia, beneficiamento, confecções e vestuário. Todas essas empresas com mais de 15 anos de atuação e média de 21 anos de vida. Os representantes, em sua maioria, possuem graduação e mais de 08 anos de atuação no mercado têxtil e no empreendimento pesquisado.

Em Salvador na Bahia, apenas um número reduzido de 32 empresas distribuídas em 06 redes contaram com o apoio das política de apoio a ASPLs. O estado priorizou os empreendimentos de beneficiamento, confecções e vestuário, etapas mais representativas econômica e socialmente em Salvador. Sete representantes de empresas desses elos foram entrevistados. As empresas possuem, em média, mais de 10 anos de atuação e média de 19 anos de vida. Boa parte dos representantes dessas organizações possui graduação e especialização e está há mais de 09 anos no mercado têxtil e na empresa analisada.

Objetivando examinar o poder das estruturas de governança sobre a regulação nos Estados, tornou-se preciso examinar primeiramente as transações dos empresários do setor têxtil. A coleta de dados se iniciou a partir do entendimento da funcionalidade/natrureza das transações realizadas nos estabelecimentos comerciais pesquisados. Foram apreciadas transações de manufatura, de fornecimento, de comercialização, e de distribuição de distintas etapas da cadeia têxtil. Buscou-se verificar se essas transações são conduzidas por mecanismos de preço (mercado), em outro extremo coordenadas por hierarquias, ou se são resultado de uma composição intermediária e mista de coordenação. Outrossim, analisou-se o custo de transação envolvido nesses negócios.

Por sua vez, visando examinar as governanças de mercado foram consideradas características como preço, transações com nota fiscal, transações via licitação, conhecimento do produto. As características consideradas para as estruturas híbridas foram a presença de contratos e parcerias ou realização de atividades conjuntas. Já como forma de identificar estruturas hierárquicas observou-se integração vertical e possível oportunismo na relação de negócios. Por fim, ponderando os custos de transação envolvidos nas transações observou-se a especificidade dos ativos, a frequência e a incerteza.

$3^{\mathrm{a}}$ etapa: Análise dos dados. A análise dos dados coletados se deu pela observância das informações qualitativas obtidas pelas entrevistas, bem como por meio de coleta bibliográfica e documental. A metodologia de análise dos dados foi a análise de conteúdo por meio do cruzamento de categorias. O método foi desenvolvido por meio de cinco etapas: Preparação das informações; Unitarização ou transformação do conteúdo em unidades; Categorização ou classificação das unidades em categorias; Descrição; Interpretação. Em seguida formatou-se um arcabouço documental, e junto aos métodos de análise as categorias da pesquisa foram criadas. Por fim, a documentação foi dividida considerando as variáveis do estudo.

$4^{\mathrm{a}}$ etapa: Escrita dos capítulos finais. O pesquisador sistematizou os dados e produziu os resultados finais e conclusões propostas pela pesquisa. 
$5^{\text {a }}$ etapa: Construção/finalização do artigo. O artigo analisa as possíveis influências da forma como são formatadas as governanças nos arranjos sobre as regras de apoio desenvolvidas nos Estados.

\section{Resultados}

Como forma de alcançar o resultado principal proposto para esta pesquisa desenvolveu-se os seguintes resultados parciais: Caracterização das transações/governança das empresas têxteis ligadas aos ASPLs na Bahia e São Paulo; Exame das regras e normas criadas como forma de regular as transações nos Estados; Descrição da influência da estrutura que compõe a governança das empresas sobre a regulação do apoio concedido aos arranjos.

\subsection{As estruturas de governança em São Paulo e na Bahia}

A composição da cadeia produtiva têxtil e de confecção é constituída por múltiplas partes industriais independentes. Contudo, o intercâmbio entre todas essas partes é essencial para o arranjo como um todo. Examina-se então as transações de manufatura, de fornecimento geral, de comercialização e de destituição em diversos elos da cadeia paulista: fiação, tecelagem, malharia, beneficiamento, confecções e vestuário. No estado da Bahia, por conta do apoio aos ASPLs do setor têxtil ter sido restrito, apenas negócios de beneficiamento, confecções e vestuário foram examinados.

As transações de manufatura dos empreendimentos de fiação e também de tecelagem envolvem, em especial, a compra de fibras têxteis. A fiação se caracteriza por ser o primeiro elo da cadeia produtiva têxtil, sendo responsável por transformar os insumos, fibras têxteis, em fios. Já a tecelagem a fibras são transformadas em tecidos planos. Em alguns casos ocorre produção conjunta de duas etapas da cadeia têxtil: fiação e tecelagem. Para as empresas pesquisadas, os negócios se dão, em sua maioria, por compras acompanhadas de notas fiscais em que o preço é essencial para a compra. No entanto, alguns poucos negócios de manufatura das empresas de fiação, a exemplo das compras de tintas, ocorrem por meio de parcerias com outra(s) empresa(s), por intermédio de redes. Assim, nesse tipo de transação, normalmente são utilizadas estruturas de governança de mercado e híbridas. As transações de manufatura ainda ocorrem com alta frequência, baixa incerteza e especificidade de ativos humanos em um número baixo de casos. Dessa forma, as transações possuem baixo custo de transação.

Também para as malharias pesquisadas a principal transação de manufatura é a compra das fibras, mas com o intuito de transformar os fios em tecido de malha. Os negócios são desenvolvidos por meio de compras diretas ao mercado e em algumas poucas oportunidades, por meio de redes (governança híbrida). Possui baixo custo de oportunidade, com alta frequência, baixa incerteza e especificidade de ativos. Por sua vez, as transações de manufatura nas empresas de beneficiamento envolvem a compra de material específico (tintas, fios para bordados, etc...). Em São Paulo o material é comprado via nota fiscal, em que o preço e a qualidade do produto definem o fornecedor. Por conseguinte, são baixos os custos de transação. Na Bahia, além das transações de mercado, alguns poucos negócios de compra de manufatura ocorrem por meio de formas híbridas (redes), aumentando um pouco os custos de transação envolvidos.

As transações de manufatura de confecções e vestuário são determinadas pelo recebimento de material das empresas de beneficiamento ou diretamente das tecelagens e malharias (tecidos e malhas beneficiados ou não). Em São Paulo, grande parte das transações é desenvolvida por intermédio do mercado, mas ocorrem muitas relações de cooperação por meio de redes. Esses e outros fatores como alta frequência, média incerteza e ocorrência de algumas especificidades de ativos físicos e dedicados também elevam um pouco os custos de transação. Na Bahia não é diferente, a grande maioria das transações também ocorre pelo mercado, existindo um número menos significativo de negócios que ocorrem pelas redes. Como consequência, têm-se custos de transação um pouco mais baixos que os desenvolvidos em São Paulo. 
Considerando agora as transações de fornecimento geral, elas envolvem a compra de mercadorias necessárias ao funcionamento das empresas, com exceção dos produtos de manufatura. Assim, foram considerados diversos tipos de transação, a exemplo da compra de material de escritório, material de limpeza, etc. Conforme verificado, todos os elos da cadeia adquirem seus produtos por meio de mecanismos de preço, com nota fiscal e havendo conhecimento do produto a ser adquirido.

Existiu, somente em dois casos, contratos e parcerias que foram estabelecidos como forma de abastecer as empresas com os produtos necessários. Apenas em uma empresa paulista de tecelagem e em uma empresa baiana de vestuários existiram transações desenvolvidas por formas híbridas, por meio de rede e de subcontratação. Isso também significou, de modo geral, baixo custo de transação nessas operações de fornecimento geral.

Por sua vez, as transações de comercialização envolvem a oferta/venda de produtos e serviços produzidos pelas organizações pesquisadas. No caso das empresas de fiação, a principal transação é a venda de algodão e de linho para empresas de confecções, brinquedos e automotivos, por exemplo. Esses negócios possuem alta ocorrência em governanças de mercado e média ocorrência em governanças híbridas por meio das redes. Ademais existe média incerteza de mercado e especificidade de ativos envolvidos nas transações, em especial porque alguns produtos são feitos sob encomenda e com características peculiares do demandante.

Já a comercialização das empresas de tecelagem consiste, em especial, na venda de tecidos de panos para a indústria de acabamento, confecções e outros ramos. Por sua vez, a comercialização das empresas de malharia consiste na venda de tecidos de malhas. Para os dois casos as características das transações possuem bastantes semelhanças, com condições de oportunismo presentes. Ocorrem com alta frequência por meio do mercado e por meio de redes e parcerias estabelecidas com empresas de beneficiamento (bordados, tinturaria, etc.), confecções, do ramo automobilístico, etc. Essas transações ainda possuem um alto nível de incerteza de mercado e ativos específicos que podem ser de marca, humana e dedicados.

Chegando a etapa final da cadeia têxtil, os produtos são preparados ao consumidor final. As transações de comercialização da etapa de confecção de São Paulo são estabelecidas por meio do mercado, mas também por meio de formas híbridas (com maior ocorrência das redes e menor ocorrência do franchising). $\mathrm{O}$ resultado da escolha dessas estruturas de governança significa também médios/altos custos de transação, por conta de existir alta frequência, média/alta incerteza de mercado e tecnológica e a presença de ativos específicos que envolvem a compra ou investimento que só foram feitos como forma de atender uma demanda de determinado(s) cliente(s), bem como ativos específicos de marca e física. O que diferencia essas mesmas transações no estado da Bahia é apenas a inexistência da franchising nessa fase. Na Bahia, as transações de comercialização ocorrem por meio do mercado e de redes, resultando numa pequena diminuição dos custos de transação envolvidos.

As transações de comercialização da etapa de vestuário consistem na venda do produto já acabado ao consumidor. Em São Paulo, assim como na Bahia, essas transações se dão, em grande maioria por intermédio do mercado, no entanto, existem alguns poucos casos as empresas estabelecem contratos/parcerias com outras empresas por meio de franchising. Os custos de transação nos dois Estados também são bastante parecidos, com alta frequência, baixo/média incerteza de mercado e a presença de ativos dedicados.

Por sim, as transações de distribuição envolvem a distribuição física ou logística dos produtos produzidos pelos empreendimentos têxteis. No que diz respeito às empresas de fiação, as transações (distribuição de produtos de linho, de algodão, fitas, etc) são realizadas por mecanismos de preço, que geralmente são cotados por correios ou transportadoras locais e não locais. Contam com alta frequência, baixa incerteza e especificidade de ativos, o que significa também baixos custos de transação. 
Em empresas da tecelagem, a distribuição dos tecidos de pano, em grande maioria, se dá por intermédio do mercado e em menor proporção por meio de subcontratação (híbrida) e também por integração vertical (hierarquia). Algumas empresas optam por fazerem a distribuição local. Essas transações ocorrem com alta frequência, média incerteza de mercado e especificidade de ativos dedicados e de localização em que os negócios com outros demandantes se tornam difíceis por conta da localização de sua empresa.

As transações de distribuição dos tecidos das empresas de malharia e também das empresas de beneficiamento de produtos (bordados, tinturaria) pesquisadas ocorrem na grande maioria das vezes via mercado. Contudo, algumas das empresas recorrem também à subcontratação, terceirizando o serviço. No que se refere aos custos de transação envolvidos, verificou-se que essas transações ocorrem com alta frequência, baixa/média incerteza e especificidade de ativos de localização.

Levando-se em consideração as transações de distribuição das empresas de confecções de São Paulo, foi possível reconhecer a utilização das três estruturas de governança. As transações ocorrem em sua maioria por via mercado e subcontratação, e em quantidades menos significativas por meio das hierarquias, em que a empresa faz a própria distribuição. Por conta disso, existem custos de transação razoáveis para essas empresas, com características de alta frequência, média incerteza e ativos específicos de localização. Na Bahia, a única exceção é a utilização das hierarquias como estrutura de governanças para essas transações. No entanto, possuem também custos de transação bastante próximos.

Por fim, as transações de distribuição das empresas de vestuário do estado de São Paulo e também da Bahia se dão, em maior número, por via da subcontratação com a terceirização do serviço que passa a ser prestado por transportadoras. Apesar disso, muitos negócios ainda são desenvolvidos por intermédio do mercado. Por conseguinte, existem custos de transação ligados ao fato da alta frequência, média incerteza e ativos específicos de localização.

A seguir, é apresentando o quadro geral das transações desenvolvidas pelos empresários nos Estados da Bahia e São Paulo. 
Quadro 1: As transações em São Paulo e na Bahia.

\begin{tabular}{|c|c|c|c|}
\hline $\begin{array}{ll}\text { Tipo } & \text { de } \\
\text { transação } & \end{array}$ & Estado & $\begin{array}{l}\text { Estrutura de governança e características das } \\
\text { transações }\end{array}$ & Custo de transação \\
\hline \multirow[t]{2}{*}{ Manufatura } & $\begin{array}{l}\text { São } \\
\text { Paulo }\end{array}$ & $\begin{array}{l}\text { Predomínio de governança de mercado } \\
\text { (mecanismo de preços e acompanhadas por nota } \\
\text { fiscal), híbrida/ redes e subcontratação }\end{array}$ & $\begin{array}{l}\text { Baixo/Médio (alta frequência, baixo/média } \\
\text { incerteza, baixa especificidade de ativos. }\end{array}$ \\
\hline & Bahia & $\begin{array}{l}\text { Predomínio de governança de mercado } \\
\text { (mecanismo preço e acompanhadas por nota } \\
\text { fiscal), híbrida/ redes. }\end{array}$ & $\begin{array}{l}\text { Baixo (alta frequência, baixa incerteza e } \\
\text { especificidade de ativos) }\end{array}$ \\
\hline \multirow[t]{2}{*}{ Fornecimento } & $\begin{array}{l}\text { São } \\
\text { Paulo }\end{array}$ & $\begin{array}{l}\text { Mercado (mecanismo preço, acompanhadas por } \\
\text { nota fiscal). }\end{array}$ & $\begin{array}{l}\text { Baixo (alta frequência, baixa incerteza, baixa } \\
\text { especificidade de ativos) }\end{array}$ \\
\hline & Bahia & $\begin{array}{l}\text { Mercado (mecanismo preço, acompanhadas por } \\
\text { nota fiscal). }\end{array}$ & $\begin{array}{l}\text { Baixo (alta frequência, baixa incerteza, baixa } \\
\text { especificidade de ativos) }\end{array}$ \\
\hline \multirow[t]{2}{*}{$\begin{array}{l}\text { Comercializa- } \\
\text { ção }\end{array}$} & $\begin{array}{l}\text { São } \\
\text { Paulo }\end{array}$ & $\begin{array}{l}\text { Mercado (mecanismo preço, acompanhadas por } \\
\text { nota fiscal), predomínio da forma híbrida/ redes e } \\
\text { franchising }\end{array}$ & $\begin{array}{l}\text { Médio/Alto (alta frequência, médio/alto(a) } \\
\text { incerteza de mercado e tecnológica, e } \\
\text { especificidade de ativos) }\end{array}$ \\
\hline & Bahia & $\begin{array}{l}\text { Mercado (mecanismo preço, acompanhadas por } \\
\text { nota fiscal), predomínio da forma híbrida (por } \\
\text { meio de redes) }\end{array}$ & $\begin{array}{l}\text { Médio/Alto (alta frequência, média alto(a) } \\
\text { incerteza de mercado e especificidade de ativos) }\end{array}$ \\
\hline \multirow[t]{2}{*}{ Distribuição } & $\begin{array}{l}\text { São } \\
\text { Paulo }\end{array}$ & $\begin{array}{l}\text { Mercado, predomínio da forma híbrida/ } \\
\text { subcontratação, hierarquia }\end{array}$ & $\begin{array}{l}\text { Médio (alta frequência, média incerteza e } \\
\text { especificidade de ativos) }\end{array}$ \\
\hline & Bahia & $\begin{array}{l}\text { Mercado, predomínio da forma híbrida/ } \\
\text { subcontratação }\end{array}$ & $\begin{array}{l}\text { Médio (alta frequência, média incerteza e } \\
\text { especificidade de ativos) }\end{array}$ \\
\hline
\end{tabular}

Fonte: Elaborado a partir da pesquisa (2019).

A partir do exame das transações e da análise do quadro pode-se empreender que as empresas pesquisadas se utilizam das diversas estruturas de governança. Em alguns casos é possível constatar inclusive a utilização de três estruturas dentro de uma única empresa. Ou seja, a mesma organização é capaz de produzir transações que ocorrem desde mecanismos de preços, passando pelas formas híbridas até uma integração vertical.

De forma geral as transações de fornecimento geral e de manufatura possuem baixo custo de transação. Os negócios relacionados à comercialização e a distribuição são transações que possuem maiores riscos e incertezas. A incerteza determinaria então a necessidade de um maior controle das transações. Dessa forma, o controle relaciona-se diretamente com a diminuição da condição de incerteza.

\subsection{Políticas de apoio e regulatórias em São Paulo e na Bahia}

Sob o entendimento do neoinstitucionalismo, as políticas públicas, inclusive as de suporte a ASPLs, são concebidas também por intermédio de instituições formais, representadas por normas e regras codificadas. A regulação aos arranjos produtivos locais ocorreu nos Estados analisados via leis, decretos e resoluções estaduais com o intuito de fomentar a economia das regiões envolvidas.

Por meio da análise de conteúdo proposta para o estudo foi possível analisar as normas e regras presentes com o intuito de verificar a normatização dada a determinados tipos de transação. Assim, foram sopesados, por intermédio de 
palavras-chave, características dessas normas e regras que regulem e/ou incitem a utilização de governanças de mercado, formas híbridas ou hierarquias.

Em São Paulo, no ano de 2008 o decreto $n^{\circ}$ 53.670, de 10 de novembro de 2008 dispõe sobre a estrutura organizacional voltada à implementação do Programa de Fortalecimento da Competitividade das Empresas Localizadas em Arranjos Produtivos do Estado de São Paulo.

Como consequência do início às ações de apoio, o decreto n $\mathrm{n}^{\circ}$ 54.654, de 7 de agosto de 2009 institui o Programa Estadual de Fomento aos Arranjos Produtivos Locais, autorizando a celebração de convênios com municípios do Estado de São Paulo e entidades que especifica, visando à transferência de recursos financeiros para o incremento das cadeias produtivas. Os municípios de todo o estado, inclusive da região têxtil de Americana (Americana, Sumaré, Nova Odessa, Hortolândia, Santa Bárbara do Oeste) passam a serem alvos de investimentos diretos do estado em suas cadeias produtivas.

As leis, resoluções e decretos paulistas citados apoiam e regulam os arranjos produtivos. A regulação formal paulista ocorreu por meio de instituições formais desenvolvidas por agentes de semelhantes estilos de governo. De forma regulatória, foram encontrados aspectos específicos que denotam uma normatização que estimula operações de mercado, mas com especial atenção às formas híbridas.

No que diz respeito às transações via mercado é possível encontrar características de regulação a essas estruturas que são definidas pelos preços competitivos. As regras definidas visam normatizar, dentre outras questões, "o aumento da competitividade das micro, pequenas e médias empresas" melhorando os preços praticados; e "a negociação de preço(...)". Outras características próprias das governanças de mercado, a exemplo de compras acompanhadas por notas fiscais e via licitação não foram claramente encontrados.

Por sua vez, como forma de regular utilização de formas híbridas, a legislação paulista estaria preocupada com aspectos relacionados à cooperação, contratos e parcerias entre empresas, diminuição do oportunismo nas relações. As políticas versam, por exemplo, a respeito do "empreendedorismo, baseado na interação e cooperação" e do fomento "a cooperação entre o setor produtivo", "estabelecimento de estratégias e investimentos conjuntos, ao compartilhamento de infraestruturas", etc. (Decreto $\mathrm{n}^{\circ}$ 54.654, de 7 de agosto de 2009).

A política pública de apoio e regulamentação a ASPLs paulista, dessa forma, concentra suas instituições formais na normatização de transações que caracterizam as estruturas de mercado, mas em especial às formas híbridas. Três importantes justificativas estariam ligadas a essa específica normatização: o fato de ser uma política que estimula a formação e desenvolvimento de arranjos, ou seja, deve incitar cooperação, parcerias, etc.; a necessidade de regular transações passíveis de relações oportunistas e que exigem maior controle dos agentes; a importância de regular e estimular as relações contratuais como forma de gerar arrecadação estadual e desenvolvimento econômico regional.

Por sua vez, no estado da Bahia, em 2006 a política pública de apoio a ASPLs denominada o Progredir passa a ser financiada pelo Banco Interamericano de Desenvolvimento (BID) por meio do Contrato de Empréstimo BR-L1023, com início previsto para julho de 2006. No ano seguinte, o decreto estadual 10.431/2007 cria o Núcleo Estadual de Apoio ao Desenvolvimento de APLs na Bahia.

Além da legislação que deu suporte aos ASPLs na Bahia, foi possível também identificar ações regulatórias e estimuladoras de formas híbridas, mas também de mercado. Nas leis e decretos baianos as governanças de mercado podem ser visualizadas por meio da normatização de características relacionadas a preços competitivos. É possível encontrar, considerando as normas e regras analisadas, passagens a respeito do da regulação de governanças de mercado. Contudo, as formas híbridas também ganham destaque na Bahia e estão normalmente relacionadas à cooperação, contratos e parcerias organizacionais, capital social, manutenção e fomento às atividades conjuntas, e oportunismo dos agentes. É possível destacar, nesse sentido, regulação à essas questões, a exemplo de "termos e as condições da mútua cooperação", "estabelecimento de 
Cooperação entre as partes convenentes"; "estímulo a redes de cooperação inter organizacionais", "desenvolvimento da cultura de cooperação", "articulação espontânea das empresas produtoras, existência de cooperação inter firmas (...) capacidade associativa e cultura de cooperação".

As estruturas híbridas representam as governanças com maior regulação e também com maior estímulo pelas legislações estaduais não apenas em São Paulo, mas também na Bahia. Apesar de condições e formas de apoio totalmente diferentes, os Estados atuam de forma semelhante e privilegiam as estruturas híbridas e de mercado. Algumas razões para esse comportamento semelhante são: o fato de as duas políticas de ASPLs e incitarem a cooperação; a importância de regular os aspectos que exigem controle dos agentes; apoiar essas estruturas pode significar também maior desenvolvimento econômico e maior arrecadação.

\subsection{Relação entre as estruturas de governança e a regulação nos Estados}

De acordo com o neoinstitucionalismo econômico as políticas públicas regulatórias e de apoio seriam influenciadas por intermédio das ações delimitadas pelas instituições formais. Dessa forma, as instituições formais também seriam capazes de recomendar novas ações para a política. Para além do descrito por North (1991), este estudo demonstra a influência das transações e estruturas de governança escolhidas pelos empresários do setor têxtil em SP e na Bahia sobre a regulação política dos ASPLs nesses Estados.

Em se tratando de arranjos produtivos locais espera-se que exista bastante relação de cooperação com associativismo, confiança e parcerias entre empresas que estimulem o trabalho conjunto e melhorem a economia local. No entanto, o exame das transações também demonstrou grande presença de condições oportunistas e incerteza nas transações. Essas condições demandam um maior controle dos agentes negociadores por meio de contratos formais ou, em alguns casos, a integração vertical, aumentando os custos de transação, em especial, em negócios relacionados à comercialização e distribuição.

Observou-se que os negócios relacionados à compra de insumos de manufatura e, em especial as compras de fornecimento geral são desenvolvidos, na maioria das vezes por meio do mercado. O que significa baixa necessidade de controle dos agentes sob as transações. Ademais, a baixa necessidade de controle também implica em menos incerteza nos negócios e menos especificidade de ativos, ou seja, menores custos de transação.

Por outro lado, as transações de comercialização e distribuição, em muitos casos, necessitam de maior controle dos agentes, em especial por condições de oportunismo, incerteza e especificidade de ativos. Por conta disso, estruturas de governança como híbridas ou hierarquias precisaram ser utilizadas, significando também maiores custos de transação envolvidos. O que fica evidenciado a respeito das transações, portanto, é que em detrimento de alguns negócios, a comercialização e a distribuição apresentam, além das maiores oportunidades de negócios do setor, as condições mais problemáticas de existir controle dos agentes econômicos. Nos casos em tela, a maior a necessidade de controle gerou estruturas de governanças predominantemente contratuais.

Já no que diz respeito à forma de regulamentação das políticas públicas em São Paulo e na Bahia foi possível identificar que em ambos os Estados existe normatização e estímulos correlacionados às transações de mercado, mas em especial às transações desenvolvidas por meio de formas híbridas (redes, franchising, subcontratação). Diante da regulação e incitação às formas híbridas de estruturas de governança, as políticas demonstram o estímulo a negócios que são estabelecidos por meio de contratos, parcerias e da realização de atividades conjuntas. Para isso, essas políticas introduzem conceitos a respeito de melhorias do capital social, incitação de confiança entre atores, associativismo e sociedade entre agentes, etc.

Notadamente as transações híbridas, estabelecidas por meio de contratos, parcerias e cooperação inter organizacionais, são as transações de maior interesse dos governos estaduais. Esses negócios seriam responsáveis por um melhor desenvolvimento da economia das regiões envolvidas no estudo (região de Americana em São Paulo e região 
metropolitana de Salvador na Bahia), bem como por importantes valores de arrecadação de impostos relativos às esses negócios.

Por meio das considerações apresentadas, a influência das governanças sobre a regulação, de forma geral, estaria contida inicialmente na necessidade de controle dos agentes em diversas transações, em especial sobre comercialização e distribuição. Esses tipos de transação, conforme observados, se dão predominantemente por meio das estruturas híbridas. Assim, os tipos de transação/governança estabelecidos pelos empresários do setor têxtil entusiasmam a regulação de formas mais contratuais por parte das políticas públicas estaduais de apoio a ASPLs, conforme quadro a seguir:

Quadro 2: Possíveis influências das transações sobre as políticas/regulação.

\begin{tabular}{|l|l|}
\hline Tipos de transações & Possíveis influências sobre as políticas/regulação \\
\hline $\begin{array}{l}\text { Transações de manufatura } \\
\text { (predominantemente } \\
\text { mercado, híbrida) }\end{array}$ & $\begin{array}{l}\text { Baixa influência. Pouca necessidade de controle, com baixa influência sobre a regulação } \\
\text { específica dessas transações }\end{array}$ \\
\hline $\begin{array}{l}\text { Transações de fornecimento } \\
\text { geral (mercado) }\end{array}$ & $\begin{array}{l}\text { Baixa influência. Pouca necessidade de controle, com baixa influência sobre a regulação } \\
\text { específica dessas transações }\end{array}$ \\
\hline $\begin{array}{l}\text { Transações de } \\
\text { comercialização (mercado, } \\
\text { com destaque para as formas } \\
\text { híbridas) }\end{array}$ & $\begin{array}{l}\text { Alta influência. Características como possibilidade de oportunismo, maior custo de } \\
\text { transação e necessidade de contratos codificados geram maior incerteza e maior } \\
\text { necessidade de controle das operações. Existiria então forte influência quanto ao } \\
\text { imperativo de regulação específica dessas transações. Além de maior regulação, essas } \\
\text { transações acabam por serem mais estimuladas diante da possibilidade de desenvolvimento } \\
\text { econômico regional e de maior arrecadação para os Estados. }\end{array}$ \\
\hline $\begin{array}{l}\text { Transações de distribuição } \\
\text { (mercado, hierarquia, com } \\
\text { destaque para as híbridas) }\end{array}$ & $\begin{array}{l}\text { Média influência. Média necessidade de controle, média necessidade de regulação. } \\
\text { Também com características de oportunismo e considerável custo de transação, } \\
\text { demandando controle e regulação das políticas de apoio. }\end{array}$ \\
\hline
\end{tabular}

Fonte: Elaborado a partir da pesquisa (2019)

O quadro demonstra, portanto, que as transações que possuem características com necessidade de controle são as que mais estimulam a regulação. Logo, as transações de comercialização e de distribuição, por meio de governanças predominantemente híbridas, representam as maiores influencias sobre as normas e regras destinadas ao apoio de arranjos produtivos locais na Bahia e em São Paulo.

\section{Considerações Finais}

O grande desafio explicativo da pesquisa e principal resultado foi demonstrar como a regulação estadual de apoio aos ASPLs pode ser influenciada pela maneira como se estrutura a governança das transações econômicas nos arranjos de Confecções na Bahia e em São Paulo.

Revelou-se então importante compreender a influencia entre determinado tipo de transação/governança e a maior ou menor regulação em políticas estaduais de apoio a ASPLs. Ou seja, identificar quais tipos de transações praticadas em um ASPL são importantes para a definição de políticas de apoio. Nesse sentido, a pesquisa verificou que as transações nesse tipo de ASPL se caracterizam nas etapas de comercialização e distribuição de produtos, gerando a necessidade de utilização de estruturas de governanças híbridas que demandam controle dos agentes envolvidos. O controle, nesse caso, surge por conta da possibilidade da incerteza e do oportunismo entre as partes, o que demanda contratos escritos e maior regulação das políticas de apoio. 
Averiguou-se ainda, com relação à regulação já presente nas políticas, que as transações híbridas são as que mais normatizadas. As leis, decretos, resoluções, etc. analisadas buscavam regular essencialmente estruturas ligadas a aspectos das formas híbridas (como contratos, parceria e cooperação).

Considerados os tipos de transação importantes para a definição das políticas (destaque para as transações de comercialização e distribuição) e as estruturas de governança com maior regulação (destaque para as formas híbridas), foi então possível chegar ao resultado proposto para este trabalho. As transações dos empresários do setor têxtil demandaram a utilização de estruturas de governanças preferencialmente híbridas e o controle exigido para essas transações (por conta da incerteza, da possibilidade de oportunismo e pelos custos de transação envolvidos) demandou também a maior necessidade de regulação, por parte das políticas de apoio, das formas híbridas. Assim, as duas políticas públicas estaduais teriam sido influenciadas pela utilização de estruturas híbridas dos empresários e regularam, por conseguinte, destacadamente as formas híbridas.

A pesquisa revelou então a influência das estruturas de governança escolhidas pelos empresários sobre a regulação do apoio a ASPLs nos Estados. E, essa influência, que ocorre inicialmente por conta da necessidade de controle dos agentes e oportunismo, é demonstrada, em especial, por meio de transações de comercialização e distribuição sobre a regulação de estruturas preferencialmente híbridas. Destarte, é possível reconhecer determinada influência das governanças escolhidas pelos empresários sobre a regulação estadual dos ASPLs na Bahia e em São Paulo, conhecendo as razões para essa influência.

Diante dos resultados expostos, foi possível chegar então a conclusão de que para além dos indivíduos, grupos e organizações, as transações econômicas e estruturas de governança das transações do ramo têxtil de São Paulo e na Bahia influenciam a regulação de políticas públicas. Essa influência ocorreu, em especial por meio de transações de comercialização e distribuição, sendo essas mesmas transações as mais reguladas pelas políticas. O que leva a crer que pode existir uma bilateralidade nessa influência. Sugere-se então como trabalho futuro o estudo da influência da regulação de políticas públicas sobre as estruturas de governança das transações econômicas. Entender essa possível bilateralidade pode ser importante no desenvolvimento de aspectos teóricos e práticos a respeito das governanças e da regulação das políticas públicas.

\section{Referências}

Amato Neto, J. (2009). Gestão de sistemas locais de produção e inovação (clusters/APLs): um modelo de referência. Atlas.

Bergamaschi, S. (2004). Modelos de gestão da terceirização de Tecnologia da Informação. 2004. 179 f. Tese (Doutorado em Administração). FEA.

BNDES. Política de apoio ao desenvolvimento de Arranjos Produtivos Locais: Termo de Referência para Política Nacional de Apoio ao Desenvolvimento de Arranjos Produtivos Locais. Versão Final. (2004). http://www.mdic.gov.br/ portalmdic/arquivos/dwnl_1289322946.pdf.

Cassiolato, J. E., \& Lastres, H. M. M. O foco em arranjos produtivos e inovativos locais de micro e pequenas empresas. $2003 \mathrm{~b}$. www.ie.ufrj.br/.../LasCas\%20seminario \%20política\%20Sebrae.pdf,

Governo do estado de São Paulo. Programa Estadual de Fomento aos APLs. http: //www.desenvolvimento.sp.gov.br/programa-estadual-de-fomento-aos- apls.

Lastres, H. M. M., \& Cassiolato J. E. (2003). Novas políticas na era do conhecimento. IE/UFRJ.

Menard, C. (2004). The economics of hybrid organizations. Journal of Institutional and Theoretical Economics. 160(3), 345-376.

Mendes-da-SIlva, W., Rossoni, L., Martin, D., \& Martelanc, R. (2008). A Influência das Redes de Relações Corporativas no Desempenho das Empresas do Novo Mercado da Bovespa. XXXII Encontro da ANPAD.

North, D. C. Institutions, institutional change and economic performance. Cambridge University Press, 1990.

North, D. C. Institutions. Journal of Economic Perspectives, 5(1), 97-112.

North, D. C. Transaction Costs, Institutions, and Economic Performance. ICS Press.

Poppo, L, \& Zenger, T. (2002).Do formal contracts and relational governance functions as substitutes or complements? Strategic Management Journal, 23(8), $707-725$

Rocha, R. (2002). A avaliação da implementação de políticas públicas a partir da perspectiva neo-institucional: avanços e validade. Cad. EBAPE.BR. 
Research, Society and Development, v. 10, n. 2, e57410212982, 2021

(CC BY 4.0) | ISSN 2525-3409 | DOI: http://dx.doi.org/10.33448/rsd-v10i2.12982

SECTI, Governo da Bahia. Programas e Projetos. Programa de Fortalecimento da Atividade Empresarial - PROGREDIR. Salvador, 2010. <http:/ /www.secti.ba.gov.br/programas-projetos/progredir-3>.

Souza, C. (2006). Políticas Públicas: uma revisão de literatura. Sociologias, 16(16), 20-45.

Vecchia, R. V. D. (2006). Arranjos Produtivos Locais como Estratégia de Desenvolvimento Regional e Local. Revista Capital Científico do Setor de Ciências Sociais Aplicadas, 4(1)

Vilella, L. E, \& Pinto, M. C. S. Governança e gestão social em redes empresariais. Revista de Administração Pública. 43(5), 1067- 1089.

Williamson, O. E. The economic institutions of capitalism: firms, markets, relational contracting. The Free Press.

Williamson, O. E. Comparative economic organization: the analysis of discrete structural alternatives. Administrative Science Quartely. 36, 269-296.

Williamson, O. E. The Mechanisms of Governance. Oxford University Press.

Williamson, O. E. Transaction cost economics and business administration. Scandinavian Journal of Management. 21(1), 19-40.

Williamson, O. E. Technology and transaction cost economics: a reply. Journal of Supply Chain Management. 44(2).

Williamson, O. E. Transaction cost economics: the origins. Journal of Retailing. 3(86), 227-231. 